\title{
Methods for assessing heat stress in preweaned dairy calves exposed to chronic heat stress or continuous cooling
}

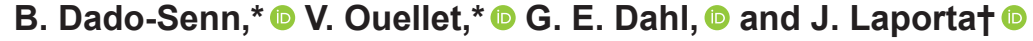 \\ Department of Animal Sciences, University of Florida, Gainesville 32611
}

\section{ABSTRACT}

Although dairy calves are more thermotolerant relative to mature cows, they are still susceptible to heat stress, as demonstrated by elevated physiological responses and reduced feed intake under high ambient temperature and relative humidity. However, indicators of heat stress have not been well-characterized in calves. Herein, we evaluated associations between environmental and thermoregulatory and productive animal-based indicators of heat stress in dairy calves exposed to chronic heat stress or continuous cooling in a subtropical climate. Holstein calves were exposed to heat stress (HT; shade of barn, $\mathrm{n}=24$ ) or continuous cooling (CL; shade of barn plus 2 fans, $n=24$ ) from 2 to $42 \mathrm{~d}$ of age. Environmental indices, including ambient temperature, relative humidity, temperature-humidity index (THI), and wind speed, and animal-based indices, including respiration (RR), heart rate (HR), rectal (RT), and skin temperature (ST) were recorded thrice daily (0900, 1300, and 1900 h). Milk replacer (MI) and grain intakes were recorded daily from 15 to $42 \mathrm{~d}$ of age. Using segmented regression models, we then estimated THI thresholds for significant changes in physiological responses. We found a strong, positive correlation between animal-based indicators (except for HR, MI, and grain intakes) and ambient temperature and THI, with the highest correlation obtained with ST and THI ( $\mathrm{r} \geq$ 0.72). Ambient temperature and ST and ambient temperature or THI and MI were the only correlations that differed between treatments. The coefficient of determination $\left(\mathrm{R}^{2}\right)$ obtained from regression analyses to model animal-based indicators was substantially improved by the inclusion of environmental indicators, with the greatest improvement achieved with THI. Overall, continuous cooling by fans promoted calf heat loss as CL calves had lower RR, RT, ST, and higher feed intake compared with HT calves. Temperature-humidity index

Received February 17, 2020.

Accepted April 14, 2020.

*These authors contributed equally to this work.

†Corresponding author: jlaporta@ufl.edu breakpoints could be determined for RT $(\mathrm{THI}=67)$, $\mathrm{RR}(\mathrm{THI}=65)$, and $\mathrm{MI}(\mathrm{THI}=82)$ in HT calves, and only for RR $(\mathrm{THI}=69)$ in CL calves. Skin temperature variables had no detectable breakpoints in either treatment due to the strong linear relationship to THI. Collectively, our results suggest that ST is appropriate to estimate chronic heat stress and that THI is the best environmental indicator of heat stress in dairy calves raised in a shaded, subtropical environment. At a practical level, calves should be closely monitored when THI reaches 65 to 69 to minimize the risk of heat stress-related impairments.

Key words: hyperthermia, temperature-humidity index, correlation, threshold

\section{INTRODUCTION}

The long-term increase in global temperatures is one of the largest challenges facing production animal agriculture. Physiological heat stress occurs when increased environmental temperature or solar radiation pushes an animal past the upper critical temperature (UCT) limit of the thermoneutral zone. To acclimate, animals adapt physiologically and behaviorally to reduce heat production and increase heat loss (Yousef, 1987). Although necessary for the survival of the animal, the acclimation response to heat stress leads to impaired milk yield, metabolic and udder health disorders, and reduced fertility in lactating dairy cows (Kadzere et al., 2002; Bernabucci et al., 2010). Dry-period heat stress can also impair a dam's milk production in the subsequent lactation with transgenerational lactational consequences for the developing fetus (Tao and Dahl, 2013; Skibiel et al., 2018; Dahl et al., 2019).

Whereas researchers have developed a comprehensive understanding of heat stress response in lactating and dry dairy cows, much remains to be understood about the effects of heat stress on the dairy calf. Preweaned calves are often not considered for heat abatement due to their larger surface-to-mass ratio and smaller heat loads (Collier et al., 1982; Broucek et al., 2009). Limited research indicates that high ambient temperature and relative humidity leads to elevated calf rectal tem- 
peratures (RT), skin temperatures (ST), and respiration rates (RR), especially when housed in calf hutch environments without supplemental shade (Spain and Spiers, 1996; Carter et al., 2014; Roland et al., 2016). Most studies emphasize calf hutch design and material or shade supplementation (Coleman et al., 1996; Carter et al., 2014; Kovács et al., 2018), whereas fewer evaluate cooled air or fan provision for heat stress abatement in individually housed calves (Stott et al., 1976; Hill et al., 2011).

A series of indicators are commonly used to estimate the degree of heat stress experienced by mature animals. Heat stress indicators can be animal-based (i.e., related to the behavior, physiology, or performance of the animal) or environmental (i.e., the thermal environment of the animal). Spain and Spiers (1996) and Kovács et al. (2018) established strong positive correlations between environmental measures, such as ambient temperature and temperature-humidity index (THI), and physiological variables, such as RR, RT, and ST in calves. However, those studies had a small sample size, only assessed supplemental shade as heat stress abatement method, or only evaluated acute responses to heat stress. A significant number of calves may be exposed to chronic levels of high ambient temperature and relative humidity because southern, southwestern, and southeastern regions of the United States can experience more than $100 \mathrm{~d}$ of heat stress annually (Ferreira et al., 2016). To our knowledge, the most optimal environmental and animal-based indicators of heat stress in dairy calves exposed to chronic heat stress or continuous cooling (i.e., fans) have yet to be determined.

Further, less is known about dairy calf environmental thresholds at which changes in physiological responses are observed. The calf environmental thermoneutral zone UCT has been documented between 25 and $32^{\circ} \mathrm{C}$ (Neuwirth et al., 1979; Spain and Spiers, 1996; Stull and Reynolds, 2008) and a physiological range of calf body temperature between 38.1 and $39.2^{\circ} \mathrm{C}$ (Moran, 2002; Piccione et al., 2003). Although THI thresholds between 68 and 72 have been well recognized for marking observed decreases in milk production in lactating cows in subtropical (Ravagnolo et al., 2000) or arid (Zimbelman et al., 2009) environments, no THI thresholds or breakpoints currently exist for the dairy calf. Identification of heat stress environmental thresholds is of importance because they can serve as a basis to monitor calf welfare and implement proper heat stress abatement strategies, especially in climates where calves are chronically exposed to high ambient temperature and relative humidity.

The objectives of the present study were to assess associations between common environmental and animal-based indicators of heat stress, study the effects of continuous cooling by fans on physiological parameters, and identify environmental thresholds of heat stress in dairy calves exposed to chronic heat stress or continuous heat stress abatement in a subtropical environment. This was accomplished by determining correlations between dairy calf animal-based [i.e., RR, RT, ST, heart rate (HR), and feed intake] and environmental indicators (i.e., ambient temperature, relative humidity, and THI), analyzing the goodness of fit of equations (including environmental measures to predict animal-based indicators), and establishing environmental breakpoints at which physiological variables begin to rise or decline in dairy calves exposed to heat stress or cooling. We hypothesized that skin temperature would show the strongest correlation with environmental measures and that correlations would vary depending on the calf thermal environment. We further hypothesized that THI would be the best environmental indicator of dairy calf heat stress, and that THI breakpoint would be set at a higher value for calves deprived of continuous cooling.

\section{MATERIALS AND METHODS}

\section{Animals and Experimental Design}

The experiment was conducted between May and November 2018 at the University of Florida Dairy Unit in Hague, Florida. All procedures were approved by the University of Florida Institutional Animal Care and Use Committee (Study \#201810202).

A detailed description of the experimental design can be found in Dado-Senn et al. (2020). In brief, 48 bull $(\mathrm{n}=26)$ and heifer $(\mathrm{n}=22)$ calves were used in this study. Within $2 \mathrm{~h}$ after birth, calves were fed 4 $\mathrm{L}$ of pooled colostrum in one feeding and their navels were dipped in $2 \%$ iodine. At $2 \mathrm{~d}$ of age $(2.4 \pm 0.2 \mathrm{~d})$, calves were assigned to 4 sand-bedded group automatic feeder pens under the shade of an open-sided barn with mobile curtains (HT; $\mathrm{n}=24$ ) or to 4 group pens under shade plus fans $(\mathbf{C L} ; \mathrm{n}=24)$ through the preweaning period (42 d of age). To account for maternal (prenatal) environments during late gestation $(\sim 46 \mathrm{~d}$ before calving), 12 calves born from prenatal HT and prenatal CL dams were assigned to each postnatal treatment. Thus, there was an equal distribution of prenatal group per pen (i.e., $1 \mathrm{HT}$ pen had $\mathrm{n}=3$ prenatal CL and $\mathrm{n}=$ 3 prenatal HT calves). Sex distribution per treatment was as follows: $\mathrm{CL}=13$ bulls, 11 heifers and HT $=13$ bulls, 11 heifers.

The arrangement of pens ( 8 pens, $\mathrm{n}=6$ calves per pen; $4.6 \times 9.1 \mathrm{~m}, 6.97 \mathrm{~m}^{2} /$ calf) is presented in Supplemental Figure S1 (https://doi.org/10.3168/jds.2020-18381). The CL pens were equipped with 1 fan positioned at 
the calf level (VMK42-2-O $107 \mathrm{~cm}$ barrel fan; Schaefer, Eau Claire, WI) and an auxiliary fan mounted above the pen $(\sim 1.8 \mathrm{~m}$ high, 36DF $91-\mathrm{cm}$ mounted direct flow circulation fan; Schaefer, Eau Claire, WI). Fans were placed on temperature-controlled timers that activated at $20^{\circ} \mathrm{C}$ ambient temperature. In the group automatic feeder pens, calves were allotted $10 \mathrm{~L} / \mathrm{d}$ of milk replacer (DeLaval CF1000X, Tumba, Sweden). Starter grain concentrate was provided in a step-up manner, from $0.2 \mathrm{~kg} / \mathrm{d}$ to $3 \mathrm{~kg} / \mathrm{d}$. Water was provided ad libitum.

\section{Environmental Indicators of Heat Stress}

Environmental measures, including ambient temperature $\left({ }^{\circ} \mathrm{C}\right)$, relative humidity $(\%)$, and THI, were recorded daily $(2-42$ d) from each pen in the morning (0700-0800 h), afternoon (1300-1400 h), and evening $(1900-2000 \mathrm{~h})$ and averaged from 3 locations within each pen (Supplemental Figure S1, https://doi.org/10 .3168/jds.2020-18381) using an air quality meter (LKC1000S+ Air Quality Monitor; Temtop, Milpitas, CA). From these variables, the daily minimum, maximum, and mean ambient temperature, relative humidity, and THI values were determined. The THI was calculated from the equation developed by the National Research Council (NRC, 1971) and recommended for use in subtropical environments by Dikmen and Hansen (2009) as shown:

$$
\begin{aligned}
\text { THI }=(1.8 \times & T+32)-[(0.55-0.0055 \times R H) \\
& +(1.8 \times T-26)],
\end{aligned}
$$

where $T=$ dry bulb temperature $\left({ }^{\circ} \mathrm{C}\right)$ and $R H=$ relative humidity (\%). Wind speed (WS, m/s) was recorded concurrently using an anemometer (MS6252A Digital Anemometer System, Proster, Miller Place, NY) placed at calf level and rotated until the maximum WS was located.

\section{Animal-Based Indicators of Heat Stress}

To assess a chronic heat stress response, physiological variables were obtained 3 times (morning, afternoon, and evening) daily from 15 to $42 \mathrm{~d}$. Respiration rate (breaths/min) was measured by counting the number of recumbent flank movements for $30 \mathrm{~s}$ and multiplying by 2 . Heart rate (beats/min) was measured using a stethoscope to count the number of resting heart beats in $30 \mathrm{~s}$ and multiplying by 2 . Rectal temperature $\left({ }^{\circ} \mathrm{C}\right)$ was measured using a rectal digital thermometer (Sharptemp V Large Animal Digital Thermometer, PBS Animal Health, Massillon, OH). Skin temperature $\left({ }^{\circ} \mathrm{C}\right)$ was measured from the ear, neck, and rump us- ing an infrared thermometer (Raytek MiniTemp MT6 Infrared Thermometer; Instrumart, South Burlington, $\mathrm{VT}$ ) placed $15 \mathrm{~cm}$ away from a shaved or unshaved 5 - $\mathrm{cm}^{2}$ site (i.e., 5 site measurements: ear, neck shaved, neck unshaved, rump shaved, and unshaved rump; depicted in Supplemental Figure S2 (https://doi.org/ 10.3168/jds.2020-18381). Milk replacer (MI, L/d) and starter concentrate $(\mathbf{G I}, \mathrm{kg} / \mathrm{d})$ intakes were recorded via automatic feeder daily (Förster Technik Software, Engen, Germany). Body weight was recorded weekly at $0,7,14,21,28,35$, and $42 \mathrm{~d}$ of age using a calibrated electronic scale, and weekly ADG was calculated from $\mathrm{BW}$ and number of days between weight measurements.

\section{Statistical Analysis}

All statistical analyses were performed in SAS (version 9.4, SAS Institute, Cary, NC). Data were first tested for covariance (Levene's test) and normality of distribution was tested by evaluating Shapiro-Wilk statistics using the Univariate procedure. To evaluate the effect of fans on the thermal environment of the animals, ambient temperature, relative humidity, and THI were averaged per day and analyzed by pen using generalized linear mixed models using the MIXED procedure of SAS with the main effects of pen (1-8), day (repeated measure), and their interaction. Statistical comparisons were made by Tukey-Kramer testing and significance was set at $P \leq 0.05$. These data are reported as least squares means \pm standard error, unless otherwise stated.

To explore the linear relationship between physiological variables and environmental measures, Pearson correlations were calculated using the CORR procedure. Correlations were carried out by treatment (CL, HT) based on individual observations measured between 15 and $42 \mathrm{~d}$. Differences among correlation coefficients between treatments were tested with a Fisher-type ztransformation and significance was set at $P \leq 0.05$. Regression analyses were performed to determine the optimal environmental indicator of heat stress in dairy calves of both treatments using the generalized linear model procedure with all animal-based indicators successively used as the dependent variable. Base model (BM) for modeling the animal-based indicators included effects of sex, age, intakes, and their interactions. Manual backward selection was then performed and only variables and interactions with $P<0.05$ were included in the BM. Milk intake was excluded from the BM when used as the dependent variable. Regression analyses were performed using the BM and several combinations of environmental measures, which included ambient temperature, relative humidity, $\mathrm{WS}^{0.5}$ and THI. The variable $\mathrm{WS}^{0.5}$ was used instead of WS 


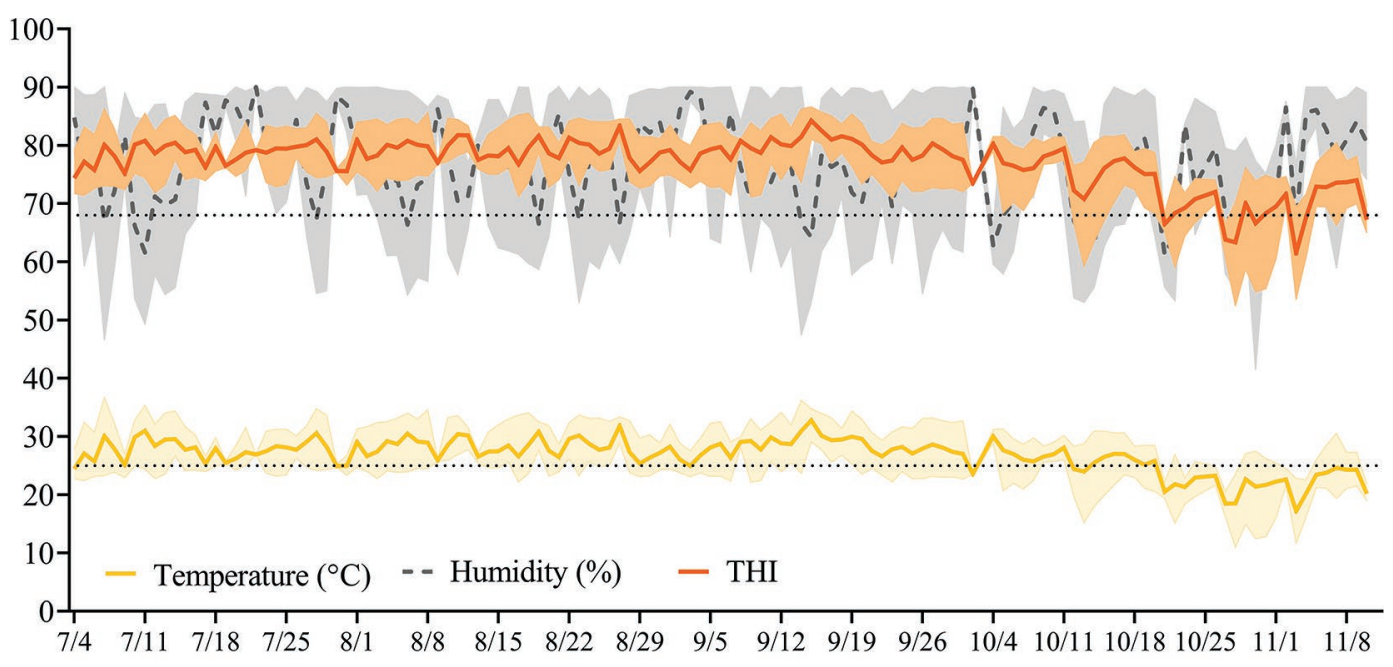

Time of Year

Figure 1. Daily minimum, maximum, and mean environmental ambient temperature $\left({ }^{\circ} \mathrm{C}\right)$, relative humidity $(\%)$, and temperature-humidity index (THI) for the duration of environmental heat stress exposure from July 4 to November 10, 2018, at the University of Florida Dairy Unit (Hague, FL). Dairy calves were exposed to continuous cooling (CL) or heat stress (HT) treatments ( $\mathrm{n}=24 /$ treatment, $2-42 \mathrm{~d}$ of age). Dotted lines indicate proposed calf thermoneutral zone upper critical temperature (UCT) and THI threshold (Stull and Reynolds, 2008; Zimbelman et al., 2009).

because it was previously reported that it represents the best fit for predicting heat flow from WS (Léger and Larochelle, 2006; Dikmen and Hansen, 2009). The goodness of fit of the regression equations was evaluated by the coefficient of determination $\left(\mathbf{R}^{2}\right)$ and root mean square error (RMSE).

Physiological differences between treatments were analyzed using generalized linear mixed models via the MIXED procedure with the main effect of treatment, day (repeated measure), and their interaction. Calf sex was included as a covariate and animal within treatment as a random effect. Statistical comparisons were made by Tukey-Kramer testing and significance was set at $P \leq 0.05$. Ultimately, significant environmental breakpoints resulting in an abrupt change in physiological response were estimated by a 2 -phase segmented regression performed with the NLIN procedure on the least squares means retrieved from the mixed models when environmental indicators were added to the model.

\section{RESULTS}

\section{Effects of Fans on the Thermal Environment}

Daily minimum, maximum, and mean ambient temperature, relative humidity, THI, and WS measured throughout the study are described in Figure 1 and Table 1. Daily ambient temperature $\left(27.2 \pm 3.7^{\circ} \mathrm{C}\right)$ and THI $(78 \pm 5)$ remained constantly above $25^{\circ} \mathrm{C}$ and 68 , respectively, until late October, when they began to fluctuate and occasionally fall under those thresholds until mid-November (Figure 1). Relative humidity (76 $\pm 11 \%$ ) varied greatly over the experimental period, but for the most part it was greater than $70 \%$. Whereas average daily ambient temperature, relative humidity, and THI did not significantly differ between treatments, average WS was significantly higher in CL pens compared with HT pens (Table $1, P<0.001$ ).

\section{Relationship Between Environmental and Animal-Based Indicators}

There was a moderate to strong, positive correlation between animal-based indicators (namely, RT, RR, and ST) and environmental measures of ambient temperature and THI with Pearson correlation coefficients ranging from $\mathrm{r}=0.31$ to 0.85 in CL calves, and from $\mathrm{r}=$ 0.31 to 0.84 in HT calves $(P<0.0001$, Figures 2 and 3$)$. In contrast, animal-based indicators showed a negative correlation with relative humidity with correlation coefficients ranging from $\mathrm{r}=-0.05$ to -0.59 in CL calves and from $\mathrm{r}=-0.01$ to -0.61 in HT calves (Figure 4). In both treatments, the strongest correlations occurred between ambient temperature or THI and ST measures including unshaved neck ( $\mathrm{r}=0.82$ to 0.85$)$ and rump ST $(r=0.83$ to 0.84$)$ and, to a lesser extent, ear ST ( $\mathrm{r}$ $=0.72$ to 0.76 ; Figures 2 and 3 ). Unshaved ST variables exhibited stronger correlations with environmental indicators relative to shaved ST variables (Table 2). Cor- 
Table 1. Environmental, animal-based nonproductivity, and productivity related indicators ${ }^{1}$ of heat stress in dairy calves exposed to continuous cooling (CL; shade and fans) or heat stress (HT; shade only)

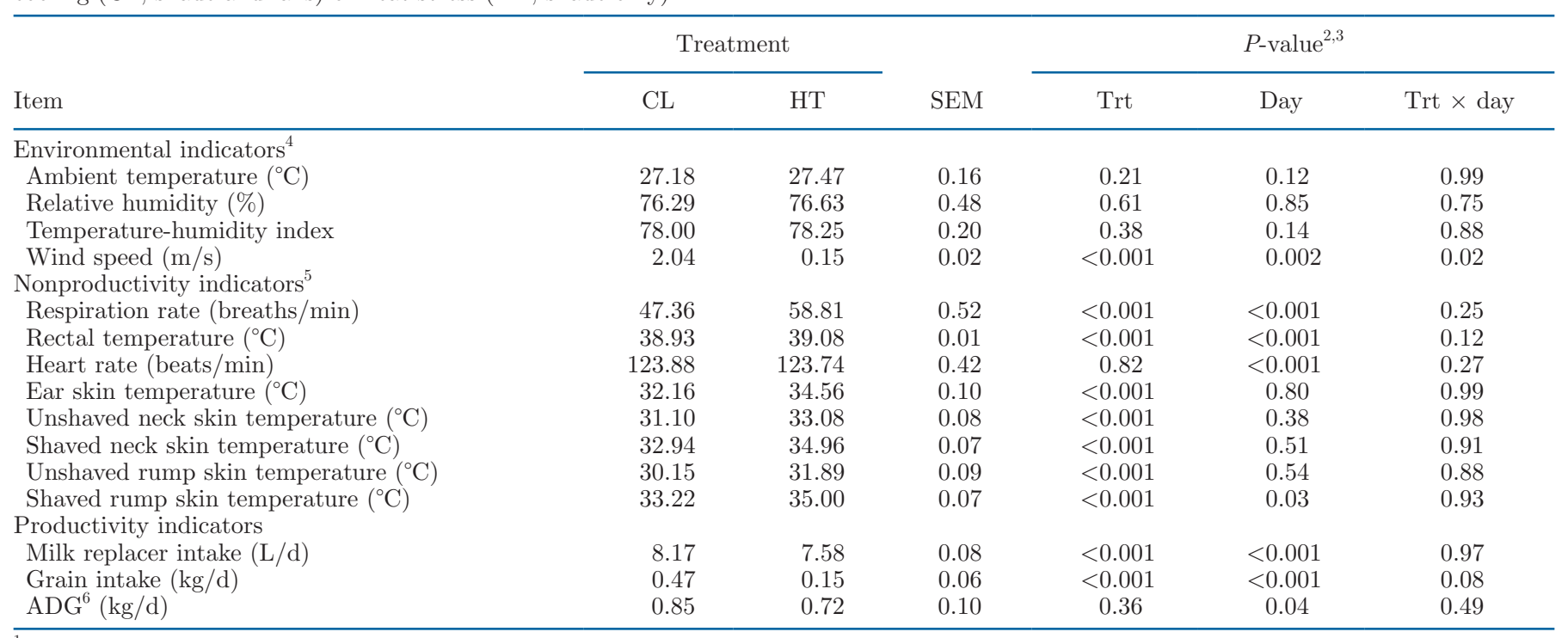

${ }^{1}$ Data were analyzed from 15 to $42 \mathrm{~d}$ and reported as LSM \pm SE of the treatment main effect.

${ }^{2}$ Trt $=$ treatment $(\mathrm{CL}, \mathrm{HT})$ main effect, Trt $\times$ day $=$ treatment $\times$ day interaction.

${ }^{3}$ Significant at $P \leq 0.05$; tendency at $0.10 \geq P>0.05$.

${ }^{4}$ Environmental indicators were measured at the pen level averaged for 3 locations within the pen and averaged per day.

${ }^{5}$ Animal-based indicators were measured at the calf level at 3 time points per day.

${ }^{6}$ Average daily gain was measured at the calf level and analyzed weekly.

relations between HR and all environmental measures evaluated herein were weak to nonexistent $(\mathrm{r}=-0.01$ to 0.05 ; Figures 2-4). Further, correlations between feed intake and environmental measures were moderate, and only HT calves had a significant negative correlation between MI and ambient temperature and THI. Thus, correlation coefficients were significantly greater for HT calves compared with CL $(\mathrm{r}=-0.12$ to -0.15 ; z-test $P$ $\leq 0.001$; Figures 2 and 3 ). Conversely, the correlation coefficients between ear ST and ambient temperature and unshaved neck ST and ambient temperature were significantly greater for CL calves compared with HT calves (z-tests $P=0.003$ and $P<0.001$, respectively; Figure 2). All other correlations coefficients between animal-based and environmental indicators showed no differences between treatments.

\section{Linear Regression of Environmental Indicators}

Tables 3 and 4 report the $\mathrm{R}^{2}$ and RMSE for predicting RT, RR, ST (ear, neck, and rump), and MI with various environmental measures in CL and HT calves, respectively. Unshaved ST was chosen over shaved ST due to their stronger correlations with environmental measures. Further, unshaved ST is likely of higher relevance to animal management. Linear regressions were not performed with HR or GI as dependent vari- ables due to weak to nonexistent correlations with the environmental indicators of heat stress. The $R^{2}$ value for the BM only (sex, age, and MI intake, interaction between sex and MI intake, and interaction between age and sex) was 0.21 and ranged from 0.08 to 0.21 and from 0.11 to 0.31 for all animal-based indicators in CL and HT calves, respectively. Adding a single environmental measure such as ambient temperature, relative humidity, or THI improved the $\mathrm{R}^{2}$ for predicting all animal-based indicators in both treatments (Tables 3 and 4). As expected, the addition of $\mathrm{WS}^{0.5}$ greatly improved $R^{2}$ in CL calves but did not cause a substantial improvement in HT calves. Notably, the $\mathrm{R}^{2}$ using THI was higher relative to the other environmental indicators. Ultimately, the largest $\mathrm{R}^{2}$ and the smallest RMSE, which are indicative of the best goodness of fit of the equation, were obtained for neck and rump ST when THI or the combination of THI and $\mathrm{WS}^{0.5}$ was included in the equation (Tables 3 and 4).

\section{Effects of Fans on Animal-Based Indicators}

Differences in calf physiological variables between HT and CL calves are reported in Table 1. Briefly, despite being exposed to similar THI, CL calves had reduced $\mathrm{RR}, \mathrm{RT}$, and ST and increased MI and GI compared with HT calves $(P<0.001)$, but there was no differ- 
$\mathbf{A}$

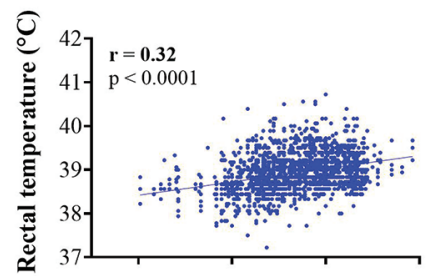

B

C

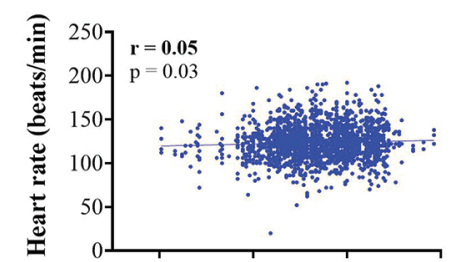

D
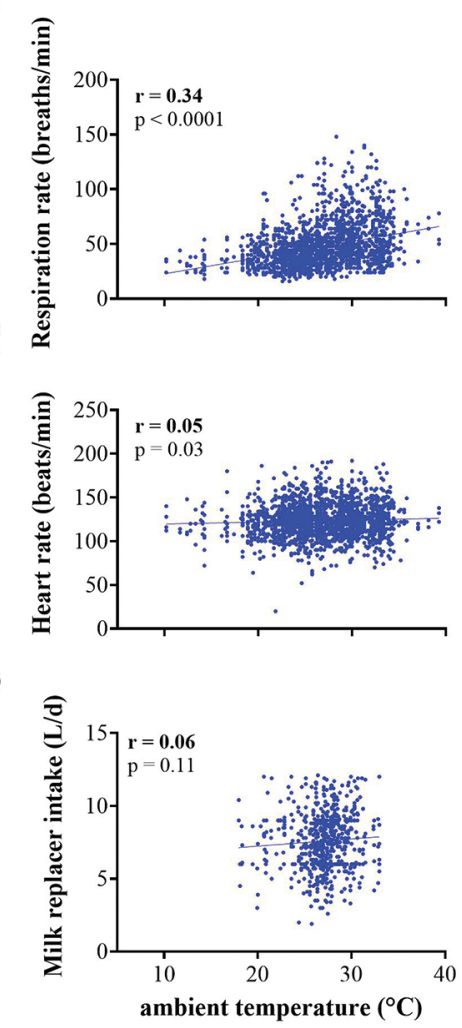

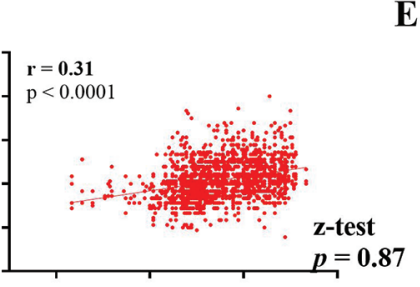

E
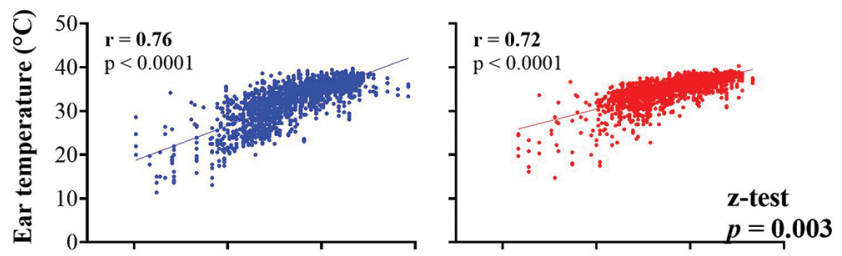

F
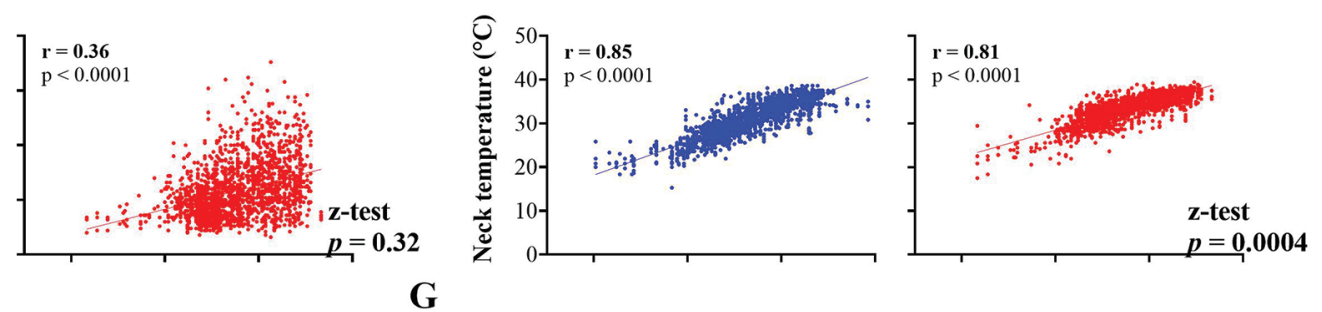

G
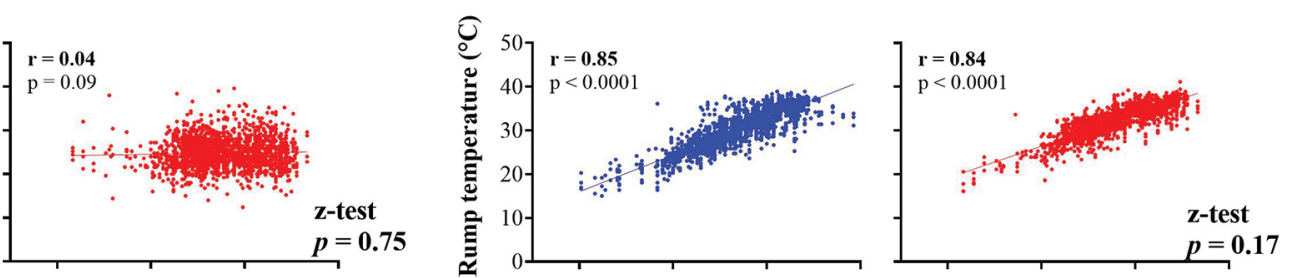

$\mathbf{H}$
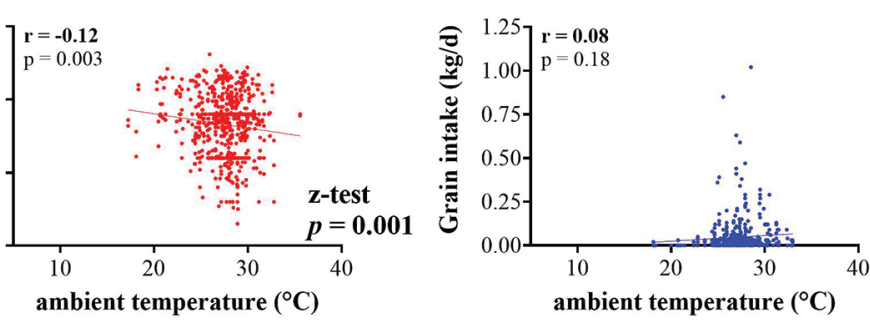

Figure 2. Relationship between (A) rectal temperature, (B) respiration rate, (C) heart rate, (D) milk replacer intake, (E) ear skin temperature, $(\mathrm{F})$ neck skin temperature, $(\mathrm{G})$ rump unshaved skin temperature, and $(\mathrm{H})$ grain intake and ambient temperature in dairy calves exposed to continuous cooling (CL, black dots; shade and fans) or heat stress (HT, gray dots; shade only) where $\mathrm{n}=24 /$ treatment. Observations were collected from 15 to $42 \mathrm{~d}$ of age. Lines represent simple linear regression equations; $P=$ significance of the correlation, and z-test $P=$ differences between correlations coefficients of both treatments.

ence between treatments for HR or ADG (Table 1). Unshaved ST was reduced by approximately $2^{\circ} \mathrm{C}$ relative to shaved ST measures, but regardless of the location or shaving for ST measurement, HT calves consistently had a ST approximately $2^{\circ} \mathrm{C}$ greater relative to CL.

\section{Temperature-Humidity Index Thresholds}

Temperature-humidity index thresholds were determined when abrupt changes in the animal-based indicators RR, RT, and MI were detected in CL and HT calves (Figure 5). Temperature-humidity was chosen over the other environmental indicators because it was the best predictor of the animal-based indicators measured in the current study. Calves exposed to chronic heat stress had a THI breakpoint of 67 for RT, whereby RT began rising at a rate of $0.03^{\circ} \mathrm{C}$ for every unit increase in THI above the threshold (Figure 5A). These HT calves also had a THI breakpoint of 65 for RR, whereby RR began rising at a rate of 2.5 breath/min for every unit increase of THI (Figure 5B). Relative to HT calves, CL calves had a higher THI threshold of 69 , whereby RR began rising at a rate of 1.4 breath/min for every increase of THI (Figure 5B). In HT calves, MI started to abruptly decrease at a THI of 82 at a rate of $0.29 \mathrm{~L} / \mathrm{d}$ (Figure $5 \mathrm{C})$. No convergence for RT or MI was reached in CL calves, indicating that no significant breakpoints (i.e., significant change in response) could be detected for those variables (Figure 5A, C). Further, no breakpoints were detected for ST measured at the ear, neck, or 
rump in both treatments within the THI range of 60 to 85 evaluated herein.

\section{DISCUSSION}

Preweaned dairy calves in subtropical environments, such as the southeastern United States, are exposed to chronic levels of heat stress with intense daily heat and humidity and minimal evening relief (West, 2003), which leads to negative thermoregulatory and productive outcomes (Coleman et al., 1996; Peña et al., 2016; López et al., 2018; Dado-Senn et al., 2020). Animalbased indicators, which represent the animal's response to an environmental challenge, and environmental indicators, such as ambient temperature and THI, are commonly used to assess the magnitude of heat stress in adult dairy cows (Galán et al., 2018; Hoffmann et al., 2019). Previous studies demonstrated strong correlations between dairy calf or feedlot steer animal-based and environmental indicators under acute nonshaded heat stress or shaded heat stress abatement (Spain and Spiers, 1996; Brown-Brandl et al., 2001; Kovács et al., 2018). However, most appropriate methods to assess dairy calf chronic heat stress remain relatively unknown. Further, THI thresholds of 52,68 , and 72 , at which rumination time or milk yield begin to decrease, were defined for lactating cows (Ravagnolo et al., 2000; Zimbelman et al., 2009; Müschner-Siemens et al., 2020). No such thresholds exist for the dairy calf, partially because economically relevant productive indicators (e.g.,
A
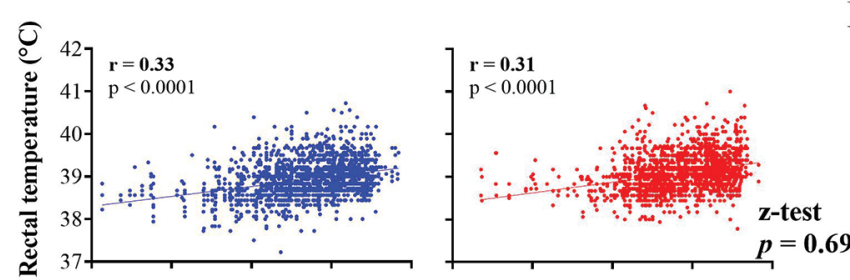

B

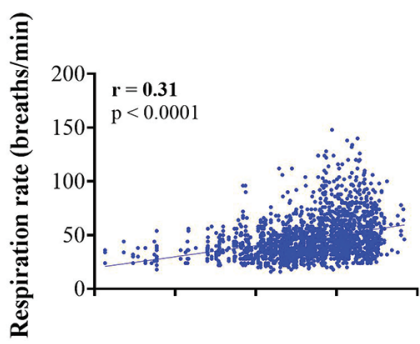

C

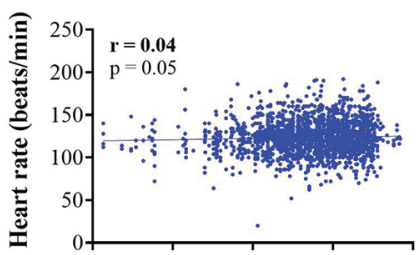

D

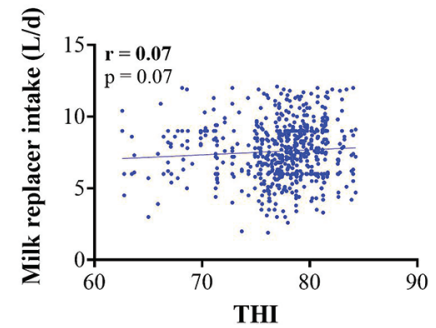

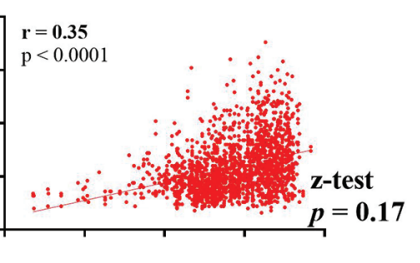

G

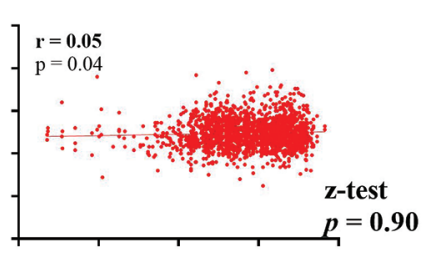

H

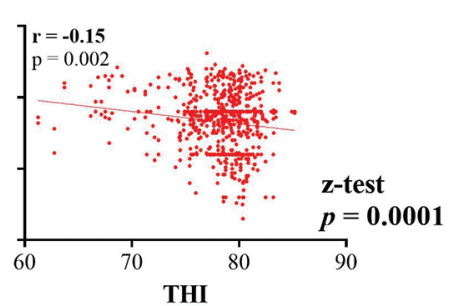

$\mathbf{E}$
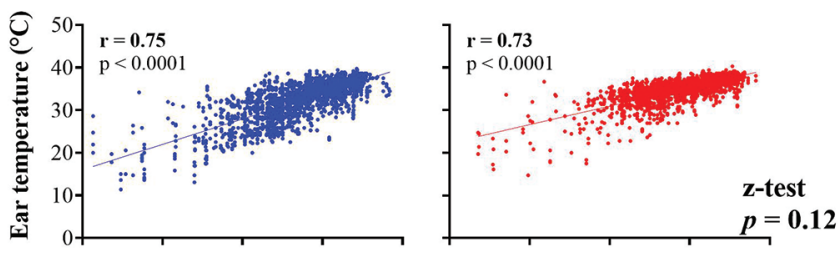

F
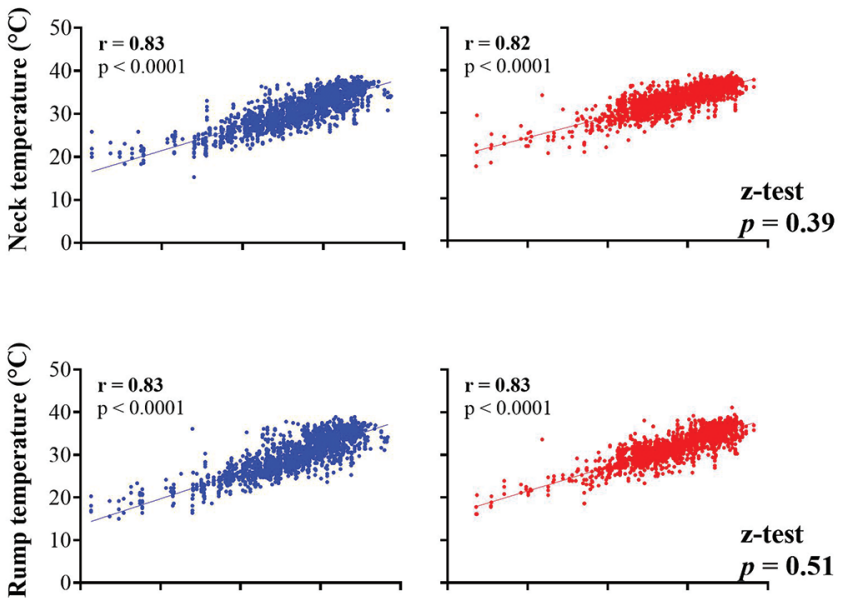

$p=0.51$

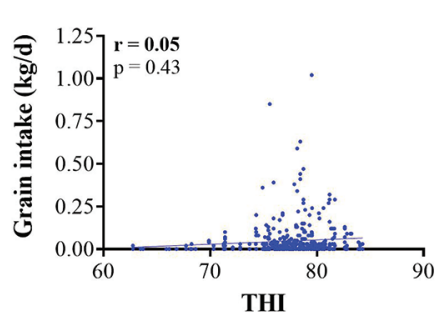

Figure 3. Relationship between (A) rectal temperature, (B) respiration rate, (C) heart rate, (D) milk replacer intake, (E) ear skin temperature, $(\mathrm{F})$ neck skin temperature, $(\mathrm{G})$ rump unshaved skin temperature, and $(\mathrm{H})$ grain intake and temperature-humidity index (THI) in dairy calves exposed to continuous cooling (CL, black dots; shade and fans) or heat stress (HT, gray dots; shade only) where $\mathrm{n}=24 /$ treatment. Observations were collected from 15 to $42 \mathrm{~d}$ of age. Lines represent simple linear regression equations; $P=$ significance of the correlation, and z-test $P=$ differences between correlations coefficients of both treatments. 
$\mathbf{A}$

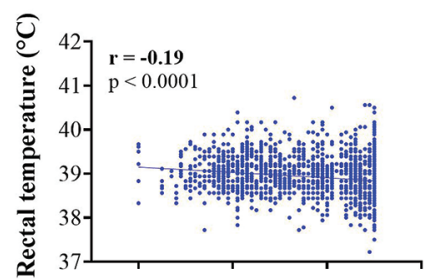

B

C

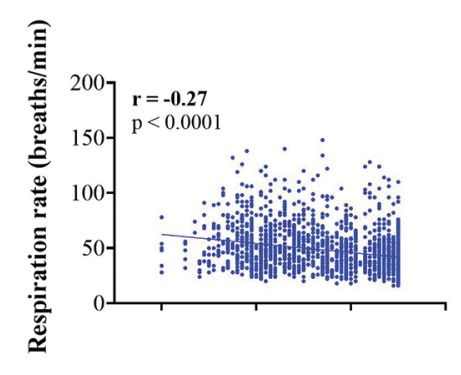

D
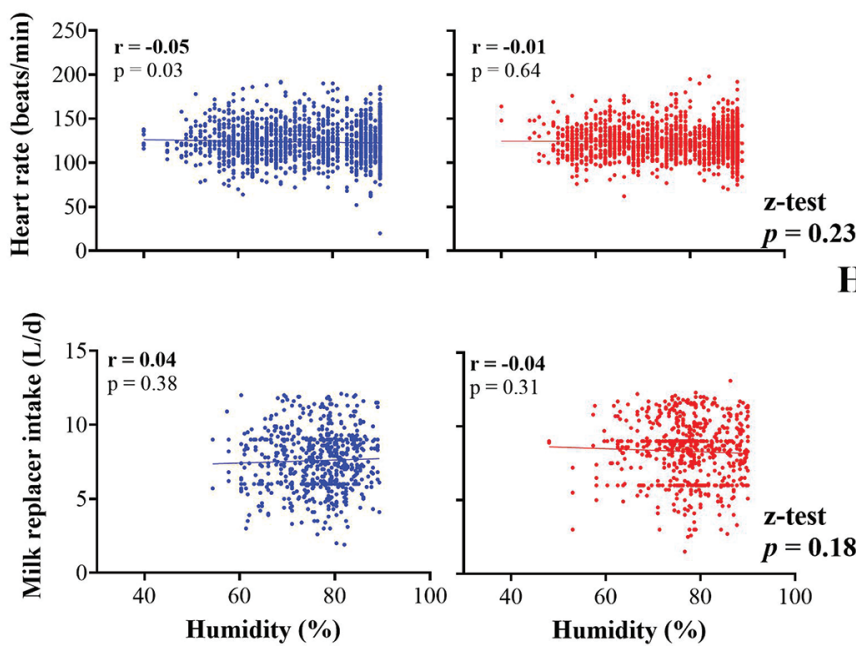

$\mathbf{H}$

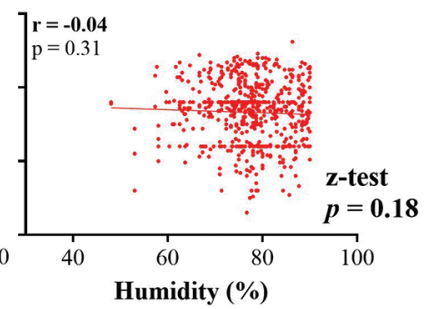

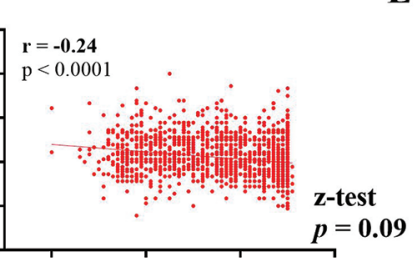

$\mathbf{E}$

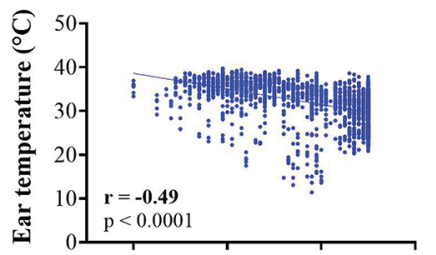

F
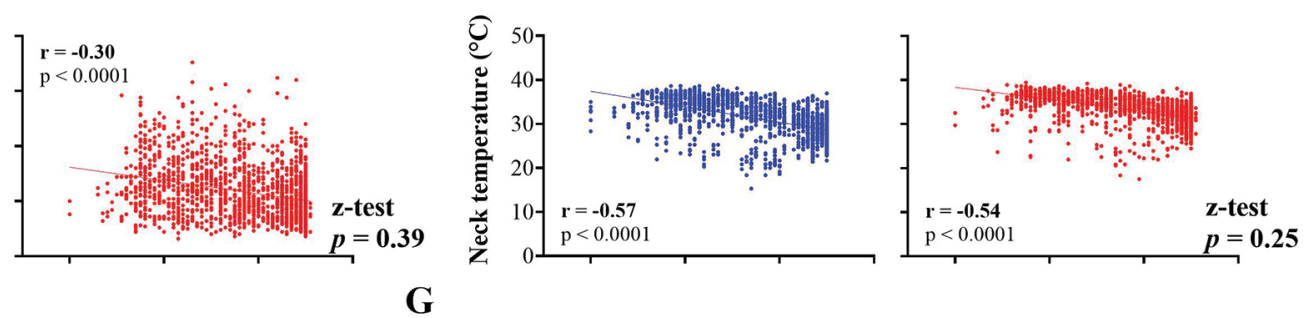

G
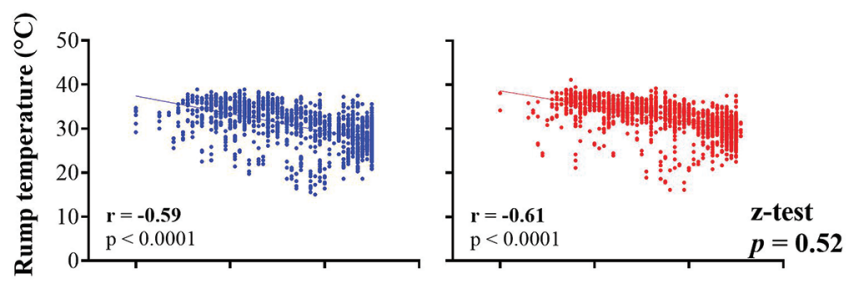

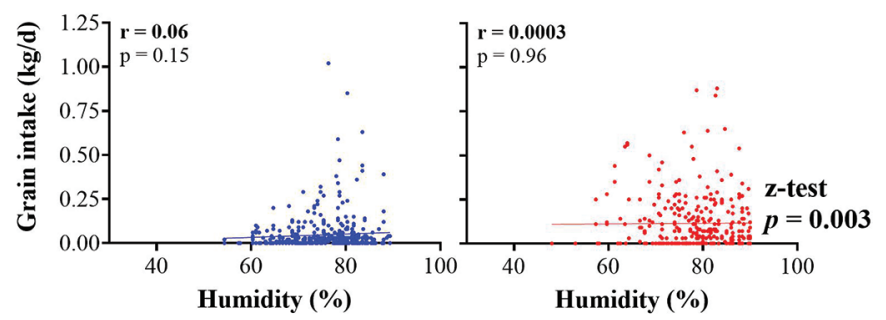

Figure 4. Relationship between (A) rectal temperature, (B) respiration rate, (C) heart rate, (D) milk replacer intake, (E) ear skin temperature, (F) neck skin temperature, $(\mathrm{G})$ rump unshaved skin temperature, and $(\mathrm{H})$ grain intake and relative humidity in dairy calves exposed to continuous cooling (CL, black dots; shade and fans) or heat stress (HT, gray dots; shade only) where $\mathrm{n}=24 /$ treatment. Observations were collected from 15 to $42 \mathrm{~d}$ of age. Lines represent simple linear regression equations; $P=$ significance of the correlation, and $\mathrm{z}$-test $P=$ differences between correlations coefficients of both treatments.

milk yield) cannot be measured, and the literature assessing heat stress in dairy calves is limited. Herein, we establish animal-based and environmental indicator associations and environmental breakpoints for dairy calves exposed to chronic heat stress or continuous heat abatement in a shaded, subtropical environment.

Calves were continuously exposed to similar levels of elevated ambient temperature and THI for $40 \mathrm{~d}$, regardless of treatment. Adding fans to the pens increased WS, but had no effect on the thermal environment (i.e., THI and ambient temperature). From July to October, values remained relatively consistent around $27^{\circ} \mathrm{C}$ with a THI of 78 . The calf environmental thermoneutral zone UCT has been proposed to range between 25 and $32^{\circ} \mathrm{C}$ (Neuwirth et al., 1979; Spain and Spiers, 1996; Stull and Reynolds, 2008), but this may vary depending on continuity of heat stress exposure, other environmental measures such as relative humidity, and level of heat stress abatement. Because of the chronic nature of the heat load in the subtropical Florida summer, it is difficult to measure reduced ambient temperature and THI to truly understand calf physiological responses to a wide range of environmental measures (West, 2003). However, this study extended into the month of November, where a drop in ambient temperature and THI allowed for a more accurate assessment of associations and environmental breakpoints at a broader range of environmental exposures (i.e., 60-85). Importantly, 
Table 2. Relationship between ear, neck, and rump (unshaved and shaved) skin temperature $\left(\mathrm{ST},{ }^{\circ} \mathrm{C}\right)$ and environmental indicators of ambient temperature, relative humidity, and temperature-humidity index (THI) in dairy calves exposed to continuous cooling (CL; shade and fans) or heat stress (HT; shade only) where $\mathrm{n}=24 /$ treatment

\begin{tabular}{lccc}
\hline Item & $\begin{array}{c}\text { Ambient } \\
\text { temperature } \\
\left({ }^{\circ} \mathrm{C}\right)\end{array}$ & $\begin{array}{c}\text { Relative } \\
\text { humidity } \\
(\%)\end{array}$ & THI \\
\hline CL & $0.76^{2}$ & -0.49 & 0.75 \\
Ear ST & 0.85 & -0.57 & 0.83 \\
Unshaved neck ST & 0.81 & -0.48 & 0.81 \\
Shaved neck ST & 0.85 & -0.59 & 0.83 \\
Unshaved rump ST & 0.80 & -0.49 & 0.79 \\
Shaved rump ST & & & \\
HT & 0.72 & -0.47 & 0.73 \\
Ear ST & 0.81 & -0.54 & 0.82 \\
Unshaved neck ST & 0.73 & -0.44 & 0.76 \\
Shaved neck ST & 0.84 & -0.61 & 0.83 \\
Unshaved rump ST & 0.74 & -0.49 & 0.75 \\
Shaved rump ST & &
\end{tabular}

${ }^{1}$ Location of ST measurements can be found in Supplemental Figure S2 (https://doi.org/10.3168/jds.2020-18381). Data were analyzed from 15 to $42 \mathrm{~d}$ and reported as LSM $\pm \mathrm{SE}$ of the treatment main effect.

${ }^{2}$ All correlations were significant $(P<0.001)$.

an equal number of $\mathrm{CL}$ and $\mathrm{HT}$ calves were exposed to this lower ambient temperature and THI window. Because ambient temperature and THI remained high for most of the trial, HT calves were exposed to elevated ambient temperature and THI both before and during indicator measurement (i.e., 15-42 d of age). In contrast, CL calves were exposed to fans with an average windspeed of $2 \mathrm{~m} / \mathrm{s}$, following lactating dairy cow WS recommendations (Berman, 2005; Silanikove et al., 2009; University of Wisconsin-Madison Dairyland Initiative, 2019).

As expected, correlations between the physiological variables RT, RR, and ST, and environmental measures of ambient temperature and THI were moderate to strong and positive, whereas correlations between these variables and relative humidity were negative. These results are consistent with a previous study of acute heat stress in a smaller pool of dairy calves in a temperate climate (Kovács et al., 2018). Interestingly, correlation coefficients for RT and ST (but not RR and HR) were relatively similar between the current study and the study conducted by Kovács et al. (2018). Differences in RR and HR correlation coefficients could be attributed to differences in climate, study duration and sample size, and possibly the technique or instruments between studies. Further, research in feedlot steers found RR to be the most optimal indicator of heat stress in a shaded vs. nonshaded study, discordant with our current findings (Brown-Brandl et al., 2001, 2005; Eigenberg et al., 2005).

Regardless of thermal exposure, the strongest correlations in the current study occurred between un- shaved ST and ambient temperature or THI, and thus ST may be the most optimal indicator of heat stress for dairy calves in a shaded, subtropical climate. The

A

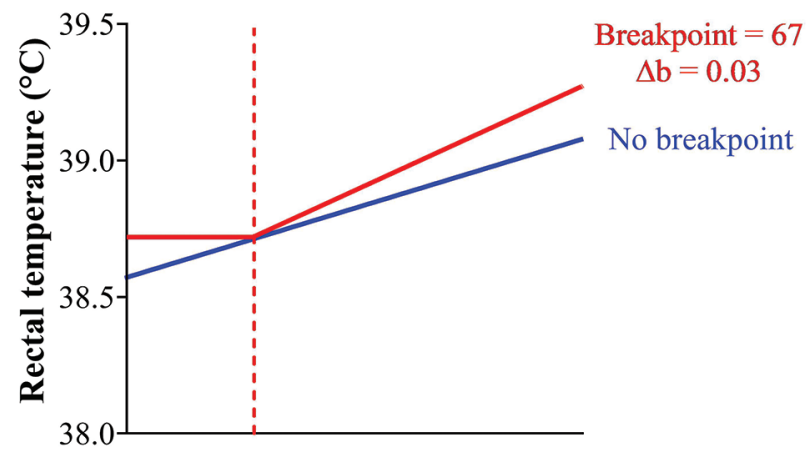

B

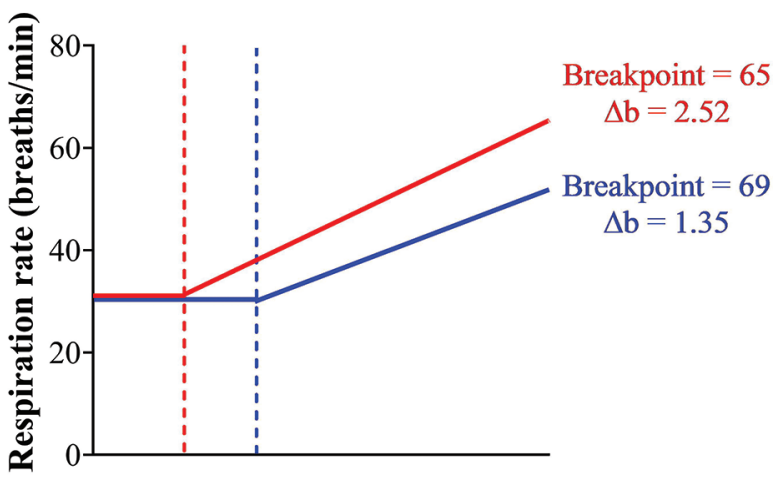

C

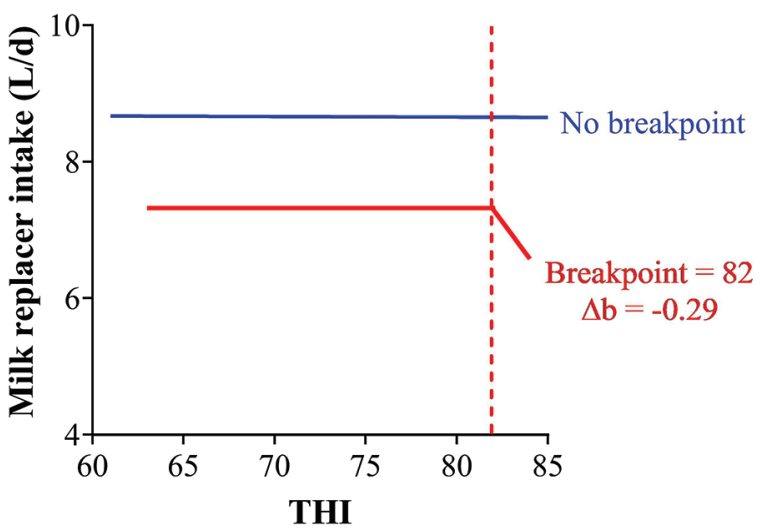

Figure 5. Segmented regressions of (A) rectal temperature $\left({ }^{\circ} \mathrm{C}\right)$, (B) respiration rate (breaths/min), and (C) daily milk replacer intake (L/d) LSM relative to temperature-humidity index (THI) in dairy calves exposed to continuous cooling (CL, black; shade and fans) or heat stress (HT, gray; shade only) where $\mathrm{n}=24$ /treatment. Vertical dashed lines indicate breakpoint at which the dependent variables changed significantly in CL calves (black) and in HT calves (gray); $\Delta \mathrm{b}$ $=$ the change in slope between $b_{1}$ (i.e., slope of data before breakpoint) and $\mathrm{b}_{2}$ (slope of data after breakpoint). 
Table 3. The $\mathrm{R}^{2}$ and root mean square error (RMSE) for predicting rectal temperature $\left({ }^{\circ} \mathrm{C}\right)$, respiration rate (breaths/min), ear skin temperature $\left({ }^{\circ} \mathrm{C}\right)$, neck skin temperature $\left({ }^{\circ} \mathrm{C}\right)$, rump skin temperature $\left({ }^{\circ} \mathrm{C}\right)$, and milk replacer intake $(\mathrm{L} / \mathrm{d})$ using various environmental variables in calves exposed to continuous cooling by shade and fans

\begin{tabular}{|c|c|c|}
\hline Model $^{1}$ & $\mathrm{R}^{2}$ & RMSE \\
\hline Rectal temperature $=\mathrm{BM}$ & 0.21 & 0.40 \\
\hline Rectal temperature $=\mathrm{BM}+\mathrm{AT}$ & 0.40 & 0.36 \\
\hline Rectal temperature $=\mathrm{BM}+\mathrm{RH}$ & 0.31 & 0.38 \\
\hline Rectal temperature $=\mathrm{BM}+\mathrm{WS}^{0.5}$ & 0.45 & 0.37 \\
\hline Rectal temperature $=\mathrm{BM}+\mathrm{THI}$ & $0.60^{2}$ & $0.34^{2}$ \\
\hline Rectal temperature $=\mathrm{BM}+\mathrm{THI}+\mathrm{WS}^{0.5}$ & $0.60^{2}$ & $0.34^{2}$ \\
\hline Respiration rate $=\mathrm{BM}$ & 0.20 & 18.64 \\
\hline Respiration rate $=\mathrm{BM}+\mathrm{AT}$ & 0.41 & 16.74 \\
\hline Respiration rate $=\mathrm{BM}+\mathrm{RH}$ & 0.33 & 17.53 \\
\hline Respiration rate $=\mathrm{BM}+\mathrm{WS}^{0.5}$ & 0.43 & 17.22 \\
\hline Respiration rate $=\mathrm{BM}+\mathrm{THI}$ & $0.64^{2}$ & $14.74^{2}$ \\
\hline Respiration rate $=\mathrm{BM}+\mathrm{THI}+\mathrm{WS}^{0.5}$ & $0.65^{2}$ & $14.64^{2}$ \\
\hline Ear temperature $=\mathrm{BM}$ & 0.09 & 4.79 \\
\hline Ear temperature $=\mathrm{BM}+\mathrm{AT}$ & 0.73 & 2.68 \\
\hline Ear temperature $=\mathrm{BM}+\mathrm{RH}$ & 0.41 & 3.90 \\
\hline Ear temperature $=\mathrm{BM}+\mathrm{WS}^{0.5}$ & 0.47 & 3.99 \\
\hline Ear temperature $=\mathrm{BM}+\mathrm{THI}$ & $0.84^{2}$ & $2.38^{2}$ \\
\hline Ear temperature $=\mathrm{BM}+\mathrm{THI}+\mathrm{WS}^{0.5}$ & $0.84^{2}$ & $2.38^{2}$ \\
\hline Neck temperature $=\mathrm{BM}$ & 0.10 & 4.08 \\
\hline Neck temperature $=\mathrm{BM}+\mathrm{AT}$ & 0.83 & 1.85 \\
\hline Neck temperature $=\mathrm{BM}+\mathrm{RH}$ & 0.52 & 3.04 \\
\hline Neck temperature $=\mathrm{BM}+\mathrm{WS}^{0.5}$ & 0.54 & 3.18 \\
\hline Neck temperature $=\mathrm{BM}+\mathrm{THI}$ & $0.91^{2}$ & $1.51^{2}$ \\
\hline Neck temperature $=\mathrm{BM}+\mathrm{THI}+\mathrm{WS}^{0.5}$ & $0.91^{2}$ & $1.51^{2}$ \\
\hline Rump temperature $=\mathrm{BM}$ & 0.08 & 4.50 \\
\hline Rump temperature $=\mathrm{BM}+\mathrm{AT}$ & 0.83 & 2.01 \\
\hline Rump temperature $=\mathrm{BM}+\mathrm{RH}$ & 0.53 & 3.25 \\
\hline Rump temperature $=\mathrm{BM}+\mathrm{WS}^{0.5}$ & 0.54 & 3.49 \\
\hline Rump temperature $=\mathrm{BM}+\mathrm{THI}$ & $0.92^{2}$ & $1.62^{2}$ \\
\hline Rump temperature $=\mathrm{BM}+\mathrm{THI}+\mathrm{WS}^{0.5}$ & $0.91^{2}$ & $1.62^{2}$ \\
\hline Milk replacer intake $=\mathrm{BM}$ & 0.11 & 1.98 \\
\hline Milk replacer intake $=\mathrm{BM}+\mathrm{AT}$ & 0.19 & 1.95 \\
\hline Milk replacer intake $=\mathrm{BM}+\mathrm{RH}$ & 0.15 & 1.96 \\
\hline Milk replacer intake $=\mathrm{BM}+\mathrm{WS}^{0.5}$ & 0.29 & 1.91 \\
\hline Milk replacer intake $=\mathrm{BM}+\mathrm{THI}$ & $0.41^{2}$ & $1.85^{2}$ \\
\hline Milk replacer intake $=\mathrm{BM}+\mathrm{THI}+\mathrm{WS}^{0.5}$ & $0.42^{2}$ & $1.84^{2}$ \\
\hline
\end{tabular}

${ }^{1}$ Base model (BM) includes adjustments of measured variables for block, sex, age, and milk intake and the interactions of sex $\times$ age and sex $\times$ milk intake. Milk intake was not included in the BM for predicting milk replacer intake. $\mathrm{AT}=$ ambient temperature $\left({ }^{\circ} \mathrm{C}\right) ; \mathrm{RH}=$ relative humidity $(\%) ; \mathrm{WS}^{0.5}=$ wind speed $(\mathrm{m} / \mathrm{s}) ; \mathrm{THI}=$ temperaturehumidity index, calculated as $(1.8 \times \mathrm{AT}+32)-[(0.55-0.0055 \times \mathrm{RH})$ $\times(1.8 \times \mathrm{AT}-26)]$

${ }^{2}$ Values represent the highest $\mathrm{R}^{2}$ and lowest RMSE.

assessment of ST requires caution, as it is not a good predictor of core body temperature (i.e., RT), which is the standard for assessing homeothermy and heat stress (Yousef, 1987; Umphrey et al., 2001). Here, we aim to look beyond the classical rise in RT and focus on initial indications of thermoregulation or thermal discomfort that may occur before alterations in RT (Van Os, 2019). Thermoregulation requires integrative signaling between core body temperature (i.e., RT) and peripheral temperature (i.e., ST) (Romanovsky, 2007). Skin temperature assessed from distal, nonhairy skin (i.e., ear ST) undergoes vast fluctuations in va-
Table 4 . The $\mathrm{R}^{2}$ and root mean square error (RMSE) for predicting rectal temperature $\left({ }^{\circ} \mathrm{C}\right)$, respiration rate (breaths/min), ear skin temperature $\left({ }^{\circ} \mathrm{C}\right)$, neck skin temperature $\left({ }^{\circ} \mathrm{C}\right)$, and rump skin temperature $\left({ }^{\circ} \mathrm{C}\right)$ using various environmental variables in calves under shade

\begin{tabular}{|c|c|c|}
\hline Model $^{1}$ & $\mathrm{R}^{2}$ & RMSE \\
\hline Rectal temperature $=\mathrm{BM}$ & 0.30 & 0.40 \\
\hline Rectal temperature $=\mathrm{BM}+\mathrm{AT}$ & 0.45 & 0.37 \\
\hline Rectal temperature $=\mathrm{BM}+\mathrm{RH}$ & 0.41 & 0.37 \\
\hline Rectal temperature $=\mathrm{BM}+\mathrm{WS}^{0.5}$ & 0.36 & 0.39 \\
\hline Rectal temperature $=\mathrm{BM}+\mathrm{THI}$ & $0.68^{2}$ & $0.32^{2}$ \\
\hline Rectal temperature $=\mathrm{BM}+\mathrm{THI}+\mathrm{WS}^{0.5}$ & $0.68^{2}$ & $0.32^{2}$ \\
\hline Respiration rate $=\mathrm{BM}$ & 0.31 & 23.33 \\
\hline Respiration rate $=\mathrm{BM}+\mathrm{AT}$ & 0.51 & 20.62 \\
\hline Respiration rate $=\mathrm{BM}+\mathrm{RH}$ & 0.45 & 21.24 \\
\hline Respiration rate $=\mathrm{BM}+\mathrm{WS}^{0.5}$ & 0.36 & 22.85 \\
\hline Respiration rate $=\mathrm{BM}+\mathrm{THI}$ & $0.68^{2}$ & $18.94^{2}$ \\
\hline Respiration rate $=\mathrm{BM}+\mathrm{THI}+\mathrm{WS}^{0.5}$ & $0.68^{2}$ & $18.92^{2}$ \\
\hline Ear temperature $=\mathrm{BM}$ & 0.22 & 3.17 \\
\hline Ear temperature $=\mathrm{BM}+\mathrm{AT}$ & 0.73 & 1.92 \\
\hline Ear temperature $=\mathrm{BM}+\mathrm{RH}$ & 0.54 & 2.46 \\
\hline Ear temperature $=\mathrm{BM}+\mathrm{WS}^{0.5}$ & 0.29 & 3.07 \\
\hline Ear temperature $=\mathrm{BM}+\mathrm{THI}$ & $0.84^{2}$ & $1.68^{2}$ \\
\hline Ear temperature $=\mathrm{BM}+\mathrm{THI}+\mathrm{WS}^{0.5}$ & $0.84^{2}$ & $1.68^{2}$ \\
\hline Neck temperature $=\mathrm{BM}$ & 0.25 & 3.06 \\
\hline Neck temperature $=\mathrm{BM}+\mathrm{AT}$ & 0.81 & 1.59 \\
\hline Neck temperature $=\mathrm{BM}+\mathrm{RH}$ & 0.65 & 2.12 \\
\hline Neck temperature $=\mathrm{BM}+\mathrm{WS}^{0.5}$ & 0.36 & 2.89 \\
\hline Neck temperature $=\mathrm{BM}+\mathrm{THI}$ & $0.91^{2}$ & $1.26^{2}$ \\
\hline Neck temperature $=\mathrm{BM}+\mathrm{THI}+\mathrm{WS}^{0.5}$ & $0.91^{2}$ & $1.26^{2}$ \\
\hline Rump temperature $=\mathrm{BM}$ & 0.21 & 3.60 \\
\hline Rump temperature $=\mathrm{BM}+\mathrm{AT}$ & 0.83 & 1.72 \\
\hline Rump temperature $=\mathrm{BM}+\mathrm{RH}$ & 0.67 & 2.36 \\
\hline Rump temperature $=\mathrm{BM}+\mathrm{WS}^{0.5}$ & 0.33 & 3.38 \\
\hline Rump temperature $=\mathrm{BM}+\mathrm{THI}$ & $0.93^{2}$ & $1.29^{2}$ \\
\hline Rump temperature $=\mathrm{BM}+\mathrm{THI}+\mathrm{WS}^{0.5}$ & $0.93^{2}$ & $1.29^{2}$ \\
\hline Milk replacer intake $=\mathrm{BM}$ & 0.11 & 1.89 \\
\hline Milk replacer intake $=\mathrm{BM}+\mathrm{AT}$ & 0.19 & 1.86 \\
\hline Milk replacer intake $=\overline{B M}+\mathrm{RH}$ & 0.16 & 1.87 \\
\hline Milk replacer intake $=\mathrm{BM}+\mathrm{WS}^{0.5}$ & 0.15 & 1.87 \\
\hline Milk replacer intake $=\mathrm{BM}+\mathrm{THI}$ & $0.45^{2}$ & $1.71^{2}$ \\
\hline Milk replacer intake $=\mathrm{BM}+\mathrm{THI}+\mathrm{WS}^{0.5}$ & $0.46^{2}$ & $1.70^{2}$ \\
\hline
\end{tabular}

${ }^{1}$ Base model (BM) includes adjustments of measured variables for block, sex, age, and milk intake and the interactions of sex $\times$ age and sex $\times$ milk intake. Milk intake was not included in the BM for predicting milk replacer intake. $\mathrm{AT}=$ ambient temperature $\left({ }^{\circ} \mathrm{C}\right) ; \mathrm{RH}=$ relative humidity $(\%) ; \mathrm{WS}^{0.5}=$ wind speed $(\mathrm{m} / \mathrm{s}) ; \mathrm{THI}=$ temperaturehumidity index, calculated as $(1.8 \times \mathrm{AT}+32)-[(0.55-0.0055 \times \mathrm{RH})$ $\times(1.8 \times \mathrm{AT}-26)]$.

${ }^{2}$ Values represent the highest $\mathrm{R}^{2}$ and lowest RMSE.

sodilation and vasoconstriction as a first response to ambient temperature to regulate core body temperature (Romanovsky, 2014). We recognize that this may not be the optimal assessment of heat stress due to strong influence of ambient temperature. However, ST can also be assessed from core body, hairy skin (i.e., rump or neck ST), which is more stable. Thermal signals from these hairy ST regions serve as important auxiliary feedback signals for regulation of behavioral and autonomic thermal responses (Romanovsky, 2014), and thus we consider them as animal-based indicators of heat stress. 
At a practical level, ST measurement is advantageous because it is rapid, noninvasive, and uses a relatively inexpensive and easy to use infrared thermometer in a shaved or unshaved area of skin. Importantly, in contrast to previous dairy calf and feedlot steer correlation studies that used artificial shade as heat stress abatement, the current study provided shade to both treatment groups and considered fan provision as the method of heat stress abatement (Spain and Spiers, 1996; Brown-Brandl et al., 2005; Kovács et al., 2018). It is likely that measuring ST in nonshaded environments would alter both ST means and correlations, as solar radiation can drastically increase radiative skin temperature. Thus, these results may not be applicable for nonshaded dairy calves.

Most correlations did not differ between HT and CL calf exposure, which is discordant with our hypothesis that correlations would vary depending on the calf thermal environment. However, calves exposed to chronic heat stress had a significant negative correlation between MI and ambient temperature and THI, whereas continuously cooled calves had an absence of correlation between these indicators. Although this study was the first to correlate dairy calf feed intake with environmental indicators, related work in dairy cows indicates that there is a strong negative correlation between ambient temperature and DMI in cows exposed to subtropical heat stress with access only to the shade of a barn (i.e., similar to our HT calves) (West et al., 2003). These results suggest that the associations between feed intake and environmental indicators could be stronger under a higher heat load, which could lead to negative productive and welfare implications for calves without continuous cooling.

Temperature-humidity index used in combination with WS explained most of the variability of the animalbased indicators measured in calves in both treatments. However, the addition of WS in regression equations that included THI only slightly improved the goodness of fit of the equations compared with when THI was used alone. This suggested that THI is a better environmental indicator to assess chronic heat stress in dairy calves in a shaded, subtropical environment relative to ambient temperature, relative humidity, and WS, in agreement with our hypothesis. In a study conducted in a more temperate climate, Kovács et al. (2018) observed that animal-based indicators correlated better with ambient temperature relative to THI. This may reflect that the effectiveness of environmental indicators to assess heat stress will vary with climate. Using RT as an end point, Dikmen and Hansen (2009) showed that, in a similar subtropical environment, the predictive value of THI was only slightly better than ambient temperature in adult lactating cows. Given that their study was conducted in mature and lactating animals, it can be assumed that the effectiveness of environmental indicators to assess heat stress will not only vary with climate, but also with the physiological stage of the animal. In both treatments, the highest $\mathrm{R}^{2}$ and lowest RMSE were obtained by the equation that included THI to predict neck and rump ST. This supported our correlation results which suggested that ST measured at the neck or the rump are indicative of thermal load in calves reared in a shaded, subtropical environment. Relative to ambient temperature and THI, WS was not an important determinant of the measured animal-based indicators in calves deprived of cooling by fans, whereas it was for calves exposed to shade and continuous cooling. Air velocity measured in HT calves' pens was consistently low $(<0.5 \mathrm{~m} / \mathrm{s})$, but it reached an average of $2.0 \mathrm{~m} / \mathrm{s}$ in pens fitted with fans. Therefore, the strong relationship between WS (expressed as $\mathrm{WS}^{0.5}$ ) and animal-based indicators measured in CL calves reflected that an air speed of 2 $\mathrm{m} / \mathrm{s}$ may be sufficient to alter thermal balance in dairy calves.

Providing heat stress abatement via fans at the calf level led to a significant reduction in mean RR, RT, and ST compared with calves provided only shade of an open-sided barn. This further confirmed our observations from the linear regressions that an air speed of $2 \mathrm{~m} / \mathrm{s}$ is sufficient for thermal balance and to promote sensible heat loss via convection in dairy calves. Notably, very few studies use forced air as a method of heat stress abatement in dairy calves (Stott et al., 1976; Hill et al., 2011). Indeed, most calf heat stress correlation papers consider supplemental shade of the hutch or supplemental artificial shade structures as heat stress abatement (Spain and Spiers, 1996; Kovács et al., 2018), but the present study considers supplemental shade to represent chronic heat stress. Thus, determining associations between physiological and environmental measures for calves under continuous cooling by fans is both novel and important for comparison with methods used for shaded calf heat-stress assessment. Further, it is noteworthy that there are few benchmarks for calf animal-based indicators, but our reported means for RT fall within the physiological range of calf body temperatures (Moran, 2002; Piccione et al., 2003).

Cooled calves consumed more milk replacer and grain from 15 to $42 \mathrm{~d}$ of age, but this did not lead to improved ADG. Although Hill et al. (2011) found that calves in a temperate climate exposed to cooling had improved ADG and feed efficiency compared with calves under no fans, other studies conducted in warmer climates in shaded vs. unshaded hutch environments found no difference in ADG (Coleman et al., 1996; Manriquez et al., 2018). We posit that differences arise because calves 
in the present study were exposed to high thermal loads with no overnight relief, and thus heat stress abatement promoted improved thermoregulation and feed intake without improving body weight gains (Dado-Senn et al., 2020).

In adult cows, THI is the most widely used environmental indicator of heat stress in scientific literature (Galán et al., 2018). Heat stress thresholds, which represent specific THI values at which an abrupt change in response is observed, are reported to vary according to cow production level, climate of interest, and physiological response measured. For instance, the heat stress threshold at which a decline in milk yield is observed in a subtropical climate has been set at THI values ranging from 68 to 72 , depending on the production level of the animal (Ravagnolo et al., 2000; Zimbelman et al., 2009). In contrast, THI values ranging from 60 to 65 were associated with a decline in milk production in temperate and continental climates (Brügemann et al., 2011; Hammami et al., 2013; Ouellet et al., 2019), and a THI value of 52 was recently associated with a reduced rumination time (Müschner-Siemens et al., 2020). Although heat stress thresholds are primarily identified for performance-related responses (i.e., decrease in milk yield), their recent application to physiological responses may help determine the proper timing of heat-abatement initiation to prevent production losses (Galán et al., 2018; Pinto et al., 2020). To date, identification of heat stress thresholds for production and physiological responses is restricted to adult dairy cows.

In the present study, THI thresholds for dairy calves could be detected only for RT, RR, and MI. Significant thresholds could not be detected for ST measures in both treatments, reflective of the strong linear relationship with THI. Significant THI threshold identification by segmented regression requires the presence of a plateau followed by an abrupt change in response due to increasing THI values. Thus, we propose that THI values (i.e., 60-85) to which the calves were exposed in the current study were too high to obtain a plateau in ST. However, this suggestion requires further studies with a wider time frame or more temperate climate to capture a broader THI range.

We demonstrated that THI thresholds varied depending on the physiological response, as RR started to increase at a lower THI relative to RT in HT calves. Moreover, THI thresholds varied according to the thermal environment of the calf, whereby calves exposed to continuous cooling had higher THI thresholds relative to calves only provided shade. This further indicated that providing fans can promote sensible heat loss and heat tolerance in dairy calves in a subtropical environment. Notably, in calves exposed to this chronic heat stress, milk replacer intake began to decrease at a THI breakpoint of 82 , which could have metabolic, productive, and welfare implications that were not assessed in this study. Finally, at a practical level, our results implied that dairy calves should be closely monitored for thermal discomfort and heat stress when THI reaches 65 for calves only provided shade, and 69 for calves exposed to continuous cooling by fans.

\section{CONCLUSIONS}

Herein, we demonstrate that shaded heat stress increases calf thermoregulatory responses, but that the use of calf-level fans in group feeding pens was effective in lowering those responses. Ambient temperature and THI correlated well with animal-based indicators of heat stress. Further, among all tested environmental indicators, addition of THI in regression equations to model the animal-based indicators obtained the highest $\mathrm{R}^{2}$ for predicting neck or rump skin temperature. Therefore, THI was determined as the most optimal environmental indicator, whereas neck and rump skin temperatures were the optimal animal-based indicators of thermal load in dairy calves in a shaded, subtropical environment. Temperature-humidity index thresholds at which the animal-based indicators started to change varied depending on the thermal environment of the calves, with CL calves (i.e., continuous cooling by fans) having higher thresholds compared with HT calves (i.e., shade of an open-sided barn). Dairy calves should be closely monitored when THI reaches 65 to 69 , depending on their thermal environment, as a rise in RT and RR is associated with thermal discomfort and heat stress. Identification of chronic heat-stress threshold in dairy calves exposed to different thermal environment is of importance to improve calf welfare and management.

\section{ACKNOWLEDGMENTS}

We thank the University of Florida Dairy Unit staff and veterinarians for their assistance in calf care. This study was supported by the USDA-Agriculture and Food Research Institute (USDA/NIFA AFRI, Washington, DC) Foundational Program Award 2019-6701529445 and Southeast Milk Check-off (Belleview, FL) awarded to J. Laporta. The authors have not stated any conflicts of interest.

\section{REFERENCES}

Berman, A. 2005. Estimates of heat stress relief needs for Holstein dairy cows. J. Anim. Sci. 83:1377-1384. https://doi.org/10.2527/ 2005.8361377x. 
Bernabucci, U., N. Lacetera, L. H. Baumgard, R. P. Rhoads, B. Ronchi, and A. Nardone. 2010. Metabolic and hormonal acclimation to heat stress in domesticated ruminants. Animal 4:1167-1183. https: //doi.org/10.1017/S175173111000090X.

Broucek, J., P. Kisac, and M. Uhrincat. 2009. Effect of hot temperatures on the hematological parameters, health and performance of calves. Int. J. Biometeorol. 53:201-208. https://doi.org/10.1007/ s00484-008-0204-1.

Brown-Brandl, T. M., R. A. Eigenberg, G. L. Hahn, and J. A. Nienaber. 2001. Correlations of respiration rate, core body temperatures, and ambient temperatures for shade and non-shaded cattle. Pages 448-454 in Sixth International Livestock Environmental Symposium. American Society Agricultural Engineers, Louisville, KY.

Brown-Brandl, T. M., R. A. Eigenberg, J. A. Nienaber, and G. L. Hahn. 2005. Dynamic response indicators of heat stress in shaded and non-shaded feedlot cattle, Part 1: Analyses of Indicators. Biosyst. Eng. 90:451-462. https://doi.org/10.1016/j.biosystemseng 2004.12.006.

Brügemann, K., E. Gernand, U. U. von Borstel, and S. König. 2011. Genetic analyses of protein yield in dairy cows applying random regression models with time-dependent and temperature $\mathrm{x}$ humidity-dependent covariates. J. Dairy Sci. 94:4129-4139. https://doi .org/10.3168/jds.2010-4063.

Carter, B. H., T. H. Friend, S. M. Garey, J. A. Sawyer, M. B. Alexander, and M. A. Tomazewski. 2014. Efficacy of reflective insulation in reducing heat stress on dairy calves housed in polyethylene calf hutches. Int. J. Biometeorol. 58:51-59. https://doi.org/10.1007/ s00484-012-0623-X.

Coleman, D. A., B. R. Moss, and T. A. Mccaskey. 1996. Supplemental shade for dairy calves reared in commercial calf hutches in a southern climate. J. Dairy Sci. 79:2038-2043. https://doi.org/10.3168/ jds.S0022-0302(96)76577-3.

Collier, R. J., S. G. Doelger, H. H. Head, W. W. Thatcher, and C. J. Wilcox. 1982. Effects of heat stress during pregnancy on maternal hormone concentrations, calf birth weight and postpartum milk yield of Holstein cows. J. Anim. Sci. 54:309-319. https://doi.org/ $10.2527 /$ jas1982.542309x.

Dado-Senn, B., L. Vega Acosta, M. Torres Rivera, S. L. Field, M. G. Marrero, B. D. Davidson, S. Tao, T. F. Fabris, G. Ortiz-Colón, G. E. Dahl, and J. Laporta. 2020. Pre- and postnatal heat stress abatement affects dairy calf thermoregulation and performance. J. Dairy Sci. 103:4822-4837. https://doi.org/10.3168/jds.2019-17926.

Dahl, G. E., A. L. Skibiel, and J. Laporta. 2019. In utero heat stress programs reduced performance and health in calves. Vet. Clin. North Am. Food Anim. Pract. 35:343-353. https://doi.org/10 .1016/j.cvfa.2019.02.005.

Dikmen, S., and P. J. Hansen. 2009. Is the temperature-humidity index the best indicator of heat stress in lactating dairy cows in a subtropical environment? J. Dairy Sci. 92:109-116. https://doi .org/10.3168/jds.2008-1370.

Eigenberg, R. A., T. M. Brown-Brandl, J. A. Nienaber, and G. L. Hahn. 2005. Dynamic response indicators of heat stress in shaded and non-shaded feedlot cattle, Part 2: Predictive relationships. Biosyst. Eng. 91:111-118. https://doi.org/10.1016/j.biosystemseng 2005.02.001.

Ferreira, F. C., R. S. Gennari, G. E. Dahl, and A. De Vries. 2016. Economic feasibility of cooling dry cows across the United States. J. Dairy Sci. 99:9931-9941. https://doi.org/10.3168/jds.2016-11566.

Galán, E., P. Llonch, A. Villagrá, H. Levit, S. Pinto, and A. del Prado. 2018. A systematic review of non-productivity related animalbased indicators of heat stress resilience in dairy cattle. PLoS One 13:e0206520. https://doi.org/10.1371/journal.pone.0206520.

Hammami, H., J. Bormann, N. M'hamdi, H. H. Montaldo, and N. Gengler. 2013. Evaluation of heat stress effects on production traits and somatic cell score of Holsteins in a temperate environment. J. Dairy Sci. 96:1844-1855. https://doi.org/10.3168/jds.2012-5947.

Hill, T. M., H. G. Bateman II, J. M. Aldrich, and R. L. Schlotterbeck. 2011. Comparisons of housing, bedding, and cooling options for dairy calves. J. Dairy Sci. 94:2138-2146. https://doi.org/10.3168/ jds.2010-3841.
Hoffmann, G., P. Herbut, S. Pinto, J. Heinicke, B. Kuhla, and T. Amon. 2019. Animal-related, non-invasive indicators for determining heat stress in dairy cows. Biosyst. Eng. https://doi.org/10 .1016/j.biosystemseng.2019.10.017.

Kadzere, C. T., M. R. Murphy, N. Silanikove, and E. Maltz. 2002. Heat stress in lactating dairy cows: A review. Livest. Prod. Sci. 77:59-91. https://doi.org/10.1016/S0301-6226(01)00330-X.

Kovács, L., F. L. Kezer, F. Ruff, V. Jurkovich, and O. Szenci. 2018. Assessment of heat stress in 7-week old dairy calves with non-invasive physiological parameters in different thermal environments. PLoS One 13:e0208528.

Léger, J., and J. Larochelle. 2006. On the importance of radiative heat exchange during nocturnal flight in birds. J. Exp. Biol. 209:103114. https://doi.org/10.1242/jeb.01964.

López, E., M. Mellado, A. M. Martínez, F. G. Véliz, J. E. García, A. de Santiago, and E. Carrillo. 2018. Stress-related hormonal alterations, growth and pelleted starter intake in pre-weaning Holstein calves in response to thermal stress. Int. J. Biometeorol. 62:493500.

Manriquez, D., H. Valenzuela, S. Paudyal, A. Velasquez, and P. J. Pinedo. 2018. Effect of aluminized reflective hutch covers on calf health and performance. J. Dairy Sci. 101:1464-1477. https://doi .org/10.3168/jds.2017-13045.

Moran, J. 2002. Calf Rearing: A Practical Guide, 2nd ed. Landlinks Press, Collingwood, Australia.

Müschner-Siemens, T., G. Hoffmann, C. Ammon, and T. Amon. 2020. Daily rumination time of lactating dairy cows under heat stress conditions. J. Therm. Biol. 88:102484. https://doi.org/10.1016/j .jtherbio.2019.102484.

Neuwirth, J. G., J. K. Norton, C. A. Rawlings, F. N. Thompson, and G. O. Ware. 1979. Physiologic responses of dairy calves to environmental heat stress. Int. J. Biometeorol. 23:243-254. https://doi .org/10.1007/BF01553775.

NRC. 1971. A Guide to Environmental Research on Animals. Natl. Acad. Sci., Washington, DC.

Ouellet, V., V. E. Cabrera, L. Fadul-Pacheco, and E. Charbonneau. 2019. The relationship between the number of consecutive days with heat stress and milk production of Holstein dairy cows raised in a humid continental climate. J. Dairy Sci. 102:8537-8545. https: //doi.org/10.3168/jds.2018-16060.

Peña, G., C. Risco, E. Kunihiro, M. J. Thatcher, and P. J. Pinedo. 2016. Effect of housing type on health and performance of preweaned dairy calves during summer in Florida. J. Dairy Sci. 99:1655-1662. https://doi.org/10.3168/jds.2015-10164.

Piccione, G., G. Caola, and R. Refinetti. 2003. Daily and estrous rhythmicity of body temperature in domestic cattle. BMC Physiol. 3:7. https://doi.org/10.1186/1472-6793-3-7.

Pinto, S., G. Hoffmann, C. Ammon, and T. Amon. 2020. Critical THI thresholds based on the physiological parameters of lactating dairy cows. J. Therm. Biol. 88:102523. https://doi.org/10.1016/j .jtherbio.2020.102523.

Ravagnolo, O., I. Misztal, and G. Hoogenboom. 2000. Genetic component of heat stress in dairy cattle, development of heat index function. J. Dairy Sci. 83:2120-2125. https://doi.org/10.3168/jds .S0022-0302(00)75094-6.

Roland, L., M. Drillich, D. Klein-Jöbstl, and M. Iwersen . 2016. Invited review: Influence of climatic conditions on the development, performance, and health of calves. J. Dairy Sci. 99:2438-2452. https://doi.org/10.3168/jds.2015-9901.

Romanovsky, A. A. 2007. Thermoregulation: Some concepts have changed. Functional architecture of the thermoregulatory system. Am. J. Physiol. Regul. Integr. Comp. Physiol. 292:R37-R46. https: //doi.org/10.1152/ajpregu.00668.2006.

Romanovsky, A. A. 2014. Skin temperature: Its role in thermoregulation. Acta Physiol. (Oxf.) 210:498-507. https://doi.org/10.1111/ apha.12231.

Silanikove, N., F. Shapiro, and D. Shinder. 2009. Acute heat stress brings down milk secretion in dairy cows by up-regulating the activity of the milk-borne negative feedback. BMC Physiol. 9:13. https://doi.org/10.1186/1472-6793-9-13. 
Skibiel, A. L., B. Dado-Senn, T. F. Fabris, G. E. Dahl, and J. Laporta. 2018. In utero exposure to thermal stress has longterm effects on mammary gland microstructure and function in dairy cattle. PLoS One 13:e0206046. https://doi.org/10.1371/journal.pone.0206046.

Spain, J. N., and D. E. Spiers. 1996. Effects of supplemental shade on thermoregulatory response of calves to heat challenge in a hutch environment. J. Dairy Sci. 79:639-646. https://doi.org/10.3168/ jds.S0022-0302(96)76409-3.

Stott, G. H., F. Wiersma, B. E. Menefee, and F. R. Radwanski. 1976. Influence of environment on passive immunity in calves. J. Dairy Sci. 59:1306-1311. https://doi.org/10.3168/jds.S0022 -0302(76)84360-3.

Stull, C., and J. Reynolds. 2008. Calf welfare. Vet. Clin. North Am. Food Anim. Pract. 24:191-203. https://doi.org/10.1016/j.cvfa .2007.12.001.

Tao, S., and G. E. Dahl. 2013. Invited review: Heat stress effects during late gestation on dry cows and their calves. J. Dairy Sci. 96:4079-4093. https://doi.org/10.3168/jds.2012-6278.

Umphrey, J. E., B. R. Moss, C. J. Wilcox, and H. H. Van Horn. 2001. Interrelationships in lactating Holsteins of rectal and skin temperatures, milk yield and composition, dry matter intake, body weight, and feed efficiency in summer in Alabama. J. Dairy Sci. 84:2680-2685. https://doi.org/10.3168/jds.S0022-0302(01)74722 $-4$.

University of Wisconsin-Madison Dairyland Initiative. 2019. Ventilation and Cooling in Adult Cattle Facilities. Accessed Feb. 14, 2020. https: / thedairylandinitiative.vetmed.wisc.edu/home/housing -module/adult-cow-housing/ventilation-and-heat-abatement/.
Van Os, J. M. C. 2019. Considerations for cooling dairy cows with water. Vet. Clin. North Am. Food Anim. Pract. 35:157-173. https: //doi.org/10.1016/j.cvfa.2018.10.009.

West, J. W. 2003. Effects of heat-stress on production in dairy cattle. J. Dairy Sci. 86:2131-2144. https://doi.org/10.3168/jds.S0022 -0302(03)73803-X.

West, J. W., B. G. Mullinix, and J. K. Bernard. 2003. Effects of hot, humid weather on milk temperature, dry matter intake, and milk yield of lactating dairy cows. J. Dairy Sci. 86:232-242. https://doi .org/10.3168/jds.S0022-0302(03)73602-9.

Yousef, M. K. 1987. Principle of Bioclimatology and Adaptation. H. D. Johnson, ed. Elsevier Science Publisher, Amsterdam, the Netherlands.

Zimbelman, R. B., R. P. Rhoads, M. L. M. L. Rhoads, G. C. Duff, L. H. Baumgard, and R. J. Collier. 2009. A re-evaluation of the impact of temperature humidity index (THI) and black globe humidity index (BGHI) on milk production in high producing dairy cows. Pages 158-169 in Southwest Nutrition \& Management Conference, Tempe, AZ. University of Arizona, Tucson.

\section{ORCIDS}

B. Dado-Senn () https://orcid.org/0000-0002-6104-7334

V. Ouellet ( https://orcid.org/0000-0003-0260-3246

G. E. Dahl $\odot$ https://orcid.org/0000-0002-2182-6317

J. Laporta @ https://orcid.org/0000-0002-3186-5360 